\title{
Impact of Deleveraging on the Liquidity Crisis of China's Stock Market
}

\author{
Zhiping Jiang \\ YinXing Hospitality Management College \\ Chengdu University of Information Technology \\ Chengdu, 611743, China \\ jiangzhiping@163.com
}

\author{
Li Tang \\ YinXing Hospitality Management College \\ Chengdu University of Information Technology \\ Chengdu, 611743, China \\ tangli_yx@163.com
}

\begin{abstract}
It is generally believed that deleveraging is the main cause of the serious liquidity crisis in the Chinese stock market in 2015. Using the real data of Chinese stock market, this paper shows that crash risk of stock market during deleveraging can be reduced by allowing short selling, and short-selling restriction is the real cause of the liquidity crisis of the Chinese stock market.
\end{abstract}

Keywords_Liquidity crisis; Deleveraging; Short selling

\section{INTRODUCTION}

Starting from the second half of 2014, the CSI 300 index of the Chinese stock market increased by $140 \%$ in less than a year, and the market value rapidly increased from less than 25 trillion Yuan to 70 trillion Yuan. Leverage trading is based on the premise that the stock market continues to rise in the short term. When the stock market is unable to sustain after reaching a high level, deleveraging and crash of prices tend to occur, leading to a serious liquidity crisis in the market.

Using a theoretical model, Kiyotak \& Moore and Geanakoplos found that the use of fire sale to describe collateral leads to the shortage of collateral after the price falls, resulting in the requirement for further asset sales ${ }^{[1-2]}$. Their model can explain the market's need to sell assets as prices fall during deleveraging, but not the buying that drove the market up. The stock market in China fell by the daily limit on a large scale. Suddenly, structural changes took place in the market as a whole, leading to a severe liquidity crisis and a precipitous fall in prices. So what is the root cause of the stock market liquidity crisis? We make an empirical analysis of this question with the real data of China's stock market, and find that deleveraging does not directly lead to the emergence of stock market liquidity crisis, and short-selling restrictions are more likely to be an important cause of stock market liquidity crisis.

\section{THEORETICAL ANALYSIS}

First, if investors are overconfident and allow a limited amount of short selling, asset prices will remain bubbly. In addition, through the introduction of deleveraging shock, it is revealed that cliff fall of stock prices and liquidity crisis in the market are caused by the overconfidence of investors with strong information crowding out investors with weak information and pushing up the market price in their leveraged

This research was financially supported by the key project of Social Science Fund of the Sichuan Provincial Education Department of China (Grant NO. 20180170) transactions ${ }^{[3]}$. If the market is faced with the deleveraging impact, the squeezed investors need to return to the market to absorb the reduced demand of the deleveraging investors. According to the demand function of the squeezed investors, the market price needs to experience a cliff fall before the squeezed investors can return to the market ${ }^{[4-5]}$.

In the case of short selling restrictions, we find that the deleveraging shock will cause liquidity shortage and cause the precipitous decline of stock price, which explains liquidity crisis in the Chinese market. The short-selling mechanism plays two roles here. Firstly, the easing of short-selling restrictions can reduce market bubbles and make the market pricing more comprehensively reflect the information and risk appetite of all investors ${ }^{[6-7]}$. As a result, the systematic pricing errors are not too large ${ }^{[8]}$. Secondly, when the market is shocked by deleveraging, short sellers can enter the market earlier, so that the market can reach the new equilibrium more smoothly ${ }^{[9-10]}$. Allowing a greater degree of short-selling exante would not only reduce the degree of market bubble, but also reduce the risk of market collapse in the deleveraging process ex-post.

Consider the following scenario: investor A holds risky assets, whose equilibrium price is $\mathrm{P}_{1 \mathrm{~A}}$. At this time, due to strong investment demand for risky assets, she will borrow money from the money market to invest when she is short of funds. When there are restrictions on short selling and market prices are high, investor $\mathrm{A}$ is more likely to borrow and invest under "the money-making effect". Considering that the market receives an exogenous impact of deleveraging, we can study whether the deleveraging impact leads to liquidity problems under the constraint of short selling ${ }^{[11]}$

Under the shock of deleveraging, investor A has to sell her risky assets to repay the debts. In this case, the market requires investor B to absorb investor A's reduced risk assets. Note that Investor B has already left the market because of restrictions on short selling, and investor A pushes investor B out of the market and pushes up the price even further. In the deleveraging stage, $\mathrm{B}$ is required to return to the market to provide liquidity and receive risky assets sold by $\mathrm{A}$, so the price of risky assets must be adjusted according to B's demand function. The price must first fall back to the position where B is willing to buy, that is, the critical price $\mathrm{N}$ where $\mathrm{B}$ just short sells. Before the price is adjusted in place, investor A is not able to sell the stock and no one accept the offer, the liquidity 
problem arises. In addition, after the price adjustment is in place, due to the requirement of A's debt repayment during deleveraging and B's investment demand of risky assets from, prices will fall further. In this article, the impact caused by price adjustment (the impact before deleveraging $\mathrm{P}_{1 \mathrm{~A}}$ and after deleveraging $\mathrm{P}_{2}, \Delta=\mathrm{P}_{1 \mathrm{~A}}-\mathrm{P}_{2}$ ) is decomposed into two parts $\Delta$ $=\Delta 1+\Delta 2$ : the first part of the price adjustment will be back to investors B's price which B is willing to buy risky assets, so it will lead to the lack of liquidity problems, known as the liquidity adjustment $\Delta 1$.The second part, investors A must sell part or all of the risk assets to repay the debt, the price will fall further from which B is willing to buy. Because it is substantial to leverage due to price adjustment, we call this part leveraged adjust $\Delta 2$. The two parts of price adjustment have different mechanisms and depend on different factors respectively, and the separate study is helpful to understand the whole process of price adjustment.

In the first stage of the stock market disaster in China, there was a common phenomenon of the limit drop in the market. A large number of selling orders piled up on the limit drop price, and the transaction volume was small ${ }^{[12]}$. At this time, the precipitous drop in price was characterized by liquidity adjustment. In the second stage, after the stock price declines continuously, some buyers start to buy. Investors forced to sell assets due to deleveraging are no longer piled up on the maximum price, and the substantial deleveraging starts. At this time, the price decline has the characteristics of leverage adjustment. In the real world, there is a combination of deleveraging and changing market information ${ }^{[13]}$, as well as people picking up stocks when the price has fallen by the daily limit, and rice adjustments are often mixed. By distinguishing between the two parts of price adjustment $\Delta 1$ and $\Delta 2$ empirically, we can get the total price adjustment $\Delta=\Delta 1+\Delta 2$.

To sum up, China's stock market has seen stock limit drop on a large scale under the impact of deleveraging. This is because investors $\mathrm{B}$ is not willing to enter the market if the market price is not adjusted in place, and investors $\mathrm{A}$ is unable to achieve the purpose of selling assets. We hypothesize the heterogeneous investment demand is generated by overconfident investors ${ }^{[14-15]}$. It provides a reasonable explanation for this phenomenon from the perspective of investors crowding out by short-selling restrictions and liquidity crisis by deleveraging shock.

\section{EMPIRICAL DESIGN}

Unlike previous bull and bear markets, leverage played an important role in driving stocks rise and fall during the 2015 crash. Investors can buy large-scale stocks through securities financing channels and over-the-counter financing channels. In terms of margin trading data, brokerages lent more than 2.2 trillion yuan at an average rate of $8.6 \%$, or $11 \%$ of the underlying market value. Over \$1.7 trillion through over-thecounter financing channels has been lent out at interest rates ranging from $13 \%$ to $20 \%$. This empirical paper divides the data into two stages. The first stage is the bubble formation stage, which started from January 1, 2015 to June 12, 2015.The second stage is the market collapse caused by deleveraging, which lasted from June 12, when the stock index reached its peak, to July 8, when the stock index temporarily stabilized, a total of 17 trading days' data. This period is free from governmental intervention and basically one could argue that the price changes were driven primarily by market forces.

At June 12, 2015, there were 895 stocks in China's stock market that are eligible for margin trading and short selling. We use these stocks from January 1, 2015 to June 12, 2015 to study the first phase of bubble formation. However, as for the research on the second stage of deleveraging, 92 stocks have been suspended, and the margin trading data of the other 54 stocks are close to 0 , so there is no deleveraging requirement. We aim to study the impact of deleveraging. After removing these stocks, the remaining 749 stocks will be used as research objects to study whether price changes can be explained by leverage ratio and short-selling degree and whether it is in line with theoretical expectations.

Next, the cross-sectional regression equation is established, and control variables are introduced to further explain that the short-selling restriction pushes up the price of risky assets, and that the price adjustment of risky assets in the deleveraging process can be explained by the leverage ratio and the short selling degree. In order to study whether the short-selling restrictions and leveraged transactions pushed up the price of risky assets, we conducted a regression analysis of the data in the first stage, during which the change rate of stock price $r$ was calculated as the dependent variable, when studying the degree of stock bubbles and the overall adjustment degree of stock prices when the bubble bursts, the cumulative price changes over a period of time are taken as the dependent variable.

Explanatory variables include the average leverage ratio of an individual stock and the maximum short-selling rate of an individual stock in this period as the constraint of short-selling, and the control variable include Fama-French three-factor $\beta_{i, 1}$, SMB ${ }_{i, 1}$, and HML, ${ }_{i, 1}$. In order to study whether the price adjustment of risky assets in the second stage of deleveraging is directly related to the short-selling degree and leverage ratio, we conduct regression analysis of the data in the second stage. The rate of change in the price of a single stock $r$ during this period is the dependent variable, and the explanatory variables are the change of leverage ratio of each stock from June 12 to July 8 and the maximum short-selling rate of individual stock as the variable of short-selling. Fama-French three-factor $\beta_{i, 2}$, $\mathrm{SMB}_{\mathrm{i}, 2}$, and HML, ${ }_{\mathrm{i}, 2}$ are the control variables.

The calculation of Fama-French three-factor for individual stocks adopts the following method. Firstly, the return $r\left(\mathrm{r}_{\mathrm{t} 1}, \mathrm{r}_{\mathrm{t} 2}\right.$, $r_{t 3}$ ) of Fama-French three-factor (market portfolio, market capitalization portfolio and book-to-market ratio portfolio) in the market is obtained from the WIND database. Then, we make a regression of the return rate of individual stock and the return rate of three-factor portfolio, and the regression coefficient is the Fama-French three-factor of individual stock. The specific model is as follows:

$$
\mathrm{y}_{\mathrm{it}}=\alpha_{\mathrm{i}}+\beta_{i} \mathrm{r}_{\mathrm{t} 1}+S M B_{\mathrm{i}} \mathrm{r}_{\mathrm{t} 2}+H M L_{\mathrm{i}} \mathrm{r}_{\mathrm{t} 3}+\varepsilon_{\mathrm{i}, \mathrm{t}}
$$

In equation (1) $y_{i t}$ is the return rate of a stock $i$ and the regression coefficient is estimated using 2 years' data. 


\section{RESUlTS AND ANALYSIS}

The daily return rate of stocks from January 1, 2013 to January 1, 2015 are respectively used to estimate the threefactor of individual stocks $\beta_{\mathrm{i}, 1}, \mathrm{SMB}{ }_{\mathrm{i}, 1}$ and $\mathrm{HML} \mathrm{i}_{\mathrm{i}, 1}$. The daily return rate data of stocks from January 1, 2013 to June 12, 2015 are used to estimate the three-factor of individual stocks $\beta_{i, 2}, S M B_{i, 2}$ and HML, ${ }_{i, 2}$.The statistical results show that, in the first period, the average price change rate of individual stock is 1.07 and the standard deviation is 0.66 . In the second period, the average price change rate of an individual stock is -0.43 and the standard deviation is 0.14. Leverage ratio and short selling ratio are respectively expressed by the ratio of margin balance and short selling balance to stock market value. The leverage peaked at 0.16. Compared with the leverage ratio, the scale of short selling is very small, with the average maximum short-selling degree only being $4.1 \times 10^{-4}$.

The first regression results are given in table I. It can be seen that, whether Fama-French three-factor control variables are added into the regression equation or not, the degree of short selling is significantly negative at the level of $0.1 \%$, indicating that if an individual stock has a greater degree of short selling, the degree of price rise tends to be higher and the degree of bubble tends to be lower, which is consistent with the theoretical analysis in this paper. In addition, for the leverage ratio, it is very significant when it is regressed without the existence of Fama-French factor, whether it is regressed alone or with short-selling restriction. Taking model 2 as an example, if the leverage ratio increases by 1 percentage point, the stock return rate will change by 1.41 percentage points under the same conditions. However, when the Fama factor is present, leverage ratio no longer significantly explains stock price changes, but short-selling restrictions are still significant. Therefore, leveraged deals are driving a bubble in individual stocks that, at first glance, is actually caused not by leveraged deals but actually by restrictions on short selling.

TABLE I. CROSS-SECTIONAL REGRESSION ANALYSIS OF BUBBLE FORMATION PERIOD OF STOCK RETURN RATE

\begin{tabular}{|c|c|c|c|c|}
\hline & Model1 & Model2 & Model3 & Model4 \\
\hline$\beta$ & $\begin{array}{c}-0.47 \underset{* *}{(4.09)} \\
* *\end{array}$ & & & $\begin{array}{c}-0.41 \\
(-4.14)^{* * *}\end{array}$ \\
\hline SMB & $\begin{array}{c}1.13 \\
(11.9) * * * \\
\end{array}$ & & & $\begin{array}{c}0.92 \\
(7.56)^{* * *} \\
\end{array}$ \\
\hline HML & $\begin{array}{c}-0.44 \\
(-4.12) * * * \\
\end{array}$ & & & $\begin{array}{c}-0.49 \\
(-5.12)^{* * *} \\
\end{array}$ \\
\hline leverage & & $\begin{array}{c}1.41(4.52) \\
* * *\end{array}$ & $\begin{array}{c}1.06 \\
(3.44)^{* * *}\end{array}$ & $\begin{array}{c}0.64 \\
(1.02)\end{array}$ \\
\hline short & & & $\begin{array}{c}-441.65 \\
(12.34)^{* * *}\end{array}$ & $\begin{array}{c}-317.08 \\
(-5.78)^{* * *}\end{array}$ \\
\hline constant & $\begin{array}{c}0.96 \\
(10.32)^{* * *}\end{array}$ & $\begin{array}{c}0.91 \\
(14.55)^{* * *}\end{array}$ & $\begin{array}{c}1.18 \\
(18.38)^{* * *} \\
\end{array}$ & $\begin{array}{c}1.36 \\
(10.81)^{* * *}\end{array}$ \\
\hline $\mathrm{F}$ & 811.6 & 1020.5 & 935.9 & 533.2 \\
\hline $\begin{array}{c}\text { Adjust- } \\
\text { R2 }\end{array}$ & 0.711 & 0.644 & 0.698 & 0.762 \\
\hline Obs & 813 & 813 & 813 & 813 \\
\hline
\end{tabular}

The second regression result is given in table II. We can find that, no matter whether the regression equation includes
Fama - French three factor as control variables, we can see that lowered leverage's contribution to the stock yield is significantly negative in the statistical sense, and the contribution of short-selling restrictions is significantly positive. It suggests that the greater of leverage scale and short-selling restrictions, the greater the risk of asset price adjustments, which is consistent with our theory. It can be seen from adjustR2 that only leverage ratio and short selling rate can explain the $90 \%$ difference in the cross section of stock returns, which is much higher than the Fama-French three-factor model, indicating that these two factors are decisive factors of market prices in the process of deleveraging.

TABLE II. CROSS SECTION REGRESSION ANALYSIS OF STOCK YIELD DURING BUBBLE BURST PERIOD

\begin{tabular}{|c|c|c|c|}
\hline & Model1 & Model2 & Model3 \\
\hline$\beta$ & $\begin{array}{c}-0.13 \\
(-4.11)^{* * *}\end{array}$ & & $\begin{array}{c}-0.090 \\
(-3.61)^{* * *}\end{array}$ \\
\hline SMB & $\begin{array}{c}-0.16 \\
(-5.51)^{* * *}\end{array}$ & & $\begin{array}{c}-0.088 \\
(-3.54)^{* * *}\end{array}$ \\
\hline HML & $\begin{array}{l}0.050 \\
(1.74)\end{array}$ & & $\begin{array}{c}0.059 \\
(2.43)^{*}\end{array}$ \\
\hline leverage & & $\begin{array}{c}-2.29 \\
(-9.61)^{* * *}\end{array}$ & $\begin{array}{c}-2.14 \\
(-6.62)^{* * *}\end{array}$ \\
\hline short & & $\begin{array}{c}107.12 \\
(10.44)^{* * *}\end{array}$ & $\begin{array}{c}93.18 \\
(6.38)^{* * *}\end{array}$ \\
\hline constant & $\begin{array}{c}-0.25 \\
(-11.26)^{* * *}\end{array}$ & $\begin{array}{c}-0.47 \\
(-31.93)^{* * *}\end{array}$ & $\begin{array}{c}-0.31 \\
(-11.54)^{* * *}\end{array}$ \\
\hline $\mathrm{F}$ & 1968 & 2977 & 1772 \\
\hline Adjust-R2 & 0.878 & 0.906 & 0.921 \\
\hline Obs & 749 & 749 & 749 \\
\hline
\end{tabular}

Asterisks indicate that the estimates are significantly different from zero at the *** $1 \%$ level, **5\% leve * $10 \%$ level.

\section{CONCLUSION}

We divide China's stock market data into two stages to study bubble formation and bubble collapse respectively. Through the empirical analysis of the stock returns of margin trading and short selling, it is found that in the early stage of bubble formation, the stock bubbles are bigger with the greater restrictions on short selling. However, after controlling the Fama-French factor, the leverage ratio has no explanatory power for the difference of stock returns on the cross section. It can be seen that it is not leverage trading that causes stock bubbles, but the restriction of short selling. In the second stage of the stock bubble collapse, the relationship between the stock price adjustment and the reduced leverage ratio and the short selling rate is in line with the theoretical expectation. Empirical analysis shows that their interpretation of the cross-sectional stock returns can reach more than $90 \%$.

Our research shows that short selling can reduce the risk of market collapse during deleveraging. Therefore, both investors and regulators should be aware that short selling is an important risk management tool in the market, rather than the cause of the market collapse. 


\section{REFERENCES}

[1] Korinek A, Simsek A. Liquidity trap and excessive leverage[J]. American Economic Review, 2016, 106(3): 699-738.

[2] J Geanakoplos. Solving the Present Crisis and Managing the Leverage Cycle[J]. Social Science Electronic Publishing, 2010, 16( Aug) :101 131.

[3] Adrian T, Fleming M, Shachar O, et al. Market liquidity after the financial crisis[J]. Annual Review of Financial Economics, 2017, 9: 4383.

[4] Brogaard J, Li D, Xia Y. Stock liquidity and default risk[J]. Journal of Financial Economics, 2017, 124(3): 486-502.

[5] N Kiyotaki,J Moore. Credit cycles[J]. Journal of political economy, 1997, 105( 2) : 211 - 248.

[6] Chang X, Chen Y, Zolotoy L. Stock liquidity and stock price crash risk[J]. Journal of financial and quantitative analysis, 2017, 52(4): 16051637.

[7] Ding R, Hou W. Retail investor attention and stock liquidity[J]. Journal of international financial markets, institutions and money, 2015, 37: 1226.

[8] Grullon G, Michenaud S, Weston J P. The real effects of short-selling constraints[J]. The Review of Financial Studies, 2015, 28(6): 1737-1767.
[9] Engelberg J E, Reed A V, Ringgenberg M C. Short - selling risk[J]. The Journal of Finance, 2018, 73(2): 755-786.

[10] Liang Y. Rebalancing, deleveraging and sustaining growth in China[J]. The Chinese Economy, 2017, 50(6): 370-380.

[11] Agarwal V, Mullally K A, Tang Y, et al. Mandatory portfolio disclosure, stock liquidity, and mutual fund performance $[\mathrm{J}]$. The Journal of Finance, 2015, 70(6): 2733-2776.

[12] Bohl M T, Reher G, Wilfling B. Short selling constraints and stock returns volatility: Empirical evidence from the German stock market[J]. Economic Modelling, 2016, 58: 159-166.

[13] Trebbi F, Xiao K. Regulation and market liquidity[J]. Management Science, 2017.

[14] Roberts I, Zurawski A. 12. changing patterns of corporate leverage in China: evidence from listed companies[J]. China's New Sources of Economic Growth, 2016: 271.

[15] De Angelis D, Grullon G, Michenaud S. The effects of short-selling threats on incentive contracts: Evidence from an experiment[J]. The Review of Financial Studies, 2017, 30(5): 1627-1659. 